\title{
Molecular cloning of the gyrA gene and characterization of its mutation in clinical isolates of quinolone-resistant Edwardsiella tarda
}

\author{
Soon Bum Shin ${ }^{1}$, Min Ho Yoo ${ }^{1}$, Joon Bum Jeong ${ }^{1}$, Young Min Kim ${ }^{2}$, \\ Joon-Ki Chung ${ }^{1}$, Min Do Huh ${ }^{1}$, Jack L. Komisar ${ }^{3}$, Hyun Do Jeong ${ }^{1, *}$ \\ ${ }^{1}$ Department of Aquatic Life Medicine, Pukyong National University, 599-1 Dae Yeon Dong, Nam Ku, Busan 608-737, \\ South Korea \\ ${ }^{2}$ Department of Biology, Yonsei University, Seoul 120-749, South Korea \\ ${ }^{3}$ Department of Immunology, Walter Reed Army Institute of Research, 503 Robert Grant Ave., Silver Spring, \\ Maryland 20910-7500, USA
}

\begin{abstract}
Knowing the entire sequence of the gene encoding the DNA gyrase Subunit A $(g y r A)$ of Edwardsiella tarda could be very useful for confirming the role of gyrA in quinolone resistance. Degenerate primers for the amplification of $g y r A$ were designed from consensus nucleotide sequences of gyrA from 9 different Gram-negative bacteria, including Escherichia coli. With these primers, DNA segments of the predicted size were amplified from the genomic DNA of E. tarda and then the flanking sequences were determined by cassette ligation-mediated polymerase chain reaction. The nucleotide sequence of gyrA was highly homologous to those of other bacterial species, in both the whole open-reading frame and the quinolone-resistance-determining region (QRDR). The 2637-bp gyrA gene encodes a protein of 878 amino acids, preceded by a putative promoter, ribosome binding site and inverted repeated sequences for cruciform structures of DNA. However, the nucleotide sequence of the flanking region did not show any homologies with those of other bacterial DNA gyrase Subunit B genes $(g y r B)$ and suggested the gyrase genes, gyrA and gyrB, are noncontinuous on the chromosome of E. tarda. All of the 12 quinolone-resistant isolates examined have an alteration within the QRDR, Ser $^{83} \rightarrow$ Arg, suggesting that, in E. tarda, resistance to quinolones is primarily related to alterations in gyrA. Transformation with the full sequence of E. tarda gyrA bearing the $\mathrm{Ser}^{83} \rightarrow \mathrm{Arg}$ mutation was able to complement the sequence of the $g y r A$ temperaturesensitive mutation in the E. coli KNK453 strain and to induce increased resistance to quinolone antibiotics at $42^{\circ} \mathrm{C}$.
\end{abstract}

KEY WORDS: Edwardsiella tarda $\cdot g y r A \cdot$ Quinolone $\cdot$ Resistance $\cdot$ Mutation

Resale or republication not permitted without written consent of the publisher

\section{INTRODUCTION}

Most quinolone resistance in bacteria can be attributed to the genes encoding DNA gyrase or Topoisomerase IV (TOPO IV). DNA gyrase is a Type II DNA topoisomerase, and is the enzyme essential for ATPdependent, negative supercoiling of DNA, which is required for DNA replication and gene transcription (Hooper 1998). Here, 2 A subunits and 2 B subunits, encoded by the gyrA and gyrB genes, respectively (2628 and $2415 \mathrm{bp}$ in Escherichia coli, respectively), make up the tetrameric active enzyme, DNA gyrase (Bébéar et al. 2000). TOPO IV, a $\mathrm{C}_{2} \mathrm{E}_{2}$ tetramer encoded by the parC and parE genes, is essential for chromosome partitioning (Adams et al. 1992). The amino acid sequences of parC and parE are homologous to some degree with those of gyrA and gyrB, respectively (Peng \& Marians 1993). The majority of the quinolone-resistance mutations in the gyrA gene are clustered in a region called the quinoloneresistance-determining region (QRDR), which includes 
the amino acid residues from 67 to 106 in the numbering system used in E. coli, and is supposed to be the site of interaction between the A subunit of gyrase and quinolones (Nakamura 1997, Horii et al. 2003). Especially, mutation at the amino acid codon $\mathrm{Ser}^{83}$ or $\mathrm{Asp}^{87}$ of this region has been described as the major mechanism for quinolone resistance in many different bacteria, including E. coli (Drlica \& Zhao 1997, Capilla et al. 2004).

The gyrA genes have been cloned and sequenced from several different bacterial species, among them Escherichia coli, Neisseria gonorrhoeae, Aeromonas salmonicida, Klebsiella pneumoniae, Helicobacter pylori, Bacillus subtilis and Campylobacter jejuni (Swanberg \& Wang 1987, Dimri \& Das 1990, Oppegard \& Sorum 1996). Substitutions at positions corresponding to $\mathrm{Ser}^{83}$ in E. coli GyrA have been detected in quinolone-resistant strains of most bacterial species. Therefore, GyrA was considered to be one of the primary targets of quinolone resistance in many bacterial species (Bébéar et al. 2000, Goni-Urriza et al. 2002).

Edwardsiella tarda, a Gram-negative bacterium of the Enterobacteriaceae family, causes hemorrhagic septicemia (edwardsiellosis) in fish, leading to extensive losses in both freshwater and marine aquaculture. The wide host range of $E$. tarda includes commercially important fishes, such as sea bream (Baxa et al. 1985), eel (Chen \& Huang 1996), flounder (Nakatsugawa 1983), tilapia (Kubota et al. 1981) and striped bass (Herman \& Bullock 1986), as well as higher vertebrates, like birds, reptiles and mammals, including humans (Janda \& Abott 1993).

Currently, Edwardsiella tarda infections in fish are treated with quinolones in many Asian countries, following the increased resistance of this bacteria to tetracyclines (Reinhardt et al. 1985, Aoki 1988, Stock \& Wiedemann 2001) that have been permitted for use in humans and aquatic animals by the Food and Drug Administration (FDA). Several strains of E. tarda isolated from diseased fish have been found to show resistance to quinolones (Aoki 1988), but nothing has been reported on the gyrA gene structure, the mutation in gyrA responsible for quinolone resistance, or other genetic bases for the decreased susceptibility to quinolones in this bacterium.

Here, we report on the cloning, sequencing and organization of the complete Edwardsiella tarda gyrA gene, as well as on the gyrA QRDRs from E. tarda isolates selected in aquatic farms for resistance to nalidixic acid.

\section{MATERIALS AND METHODS}

Bacterial cultures and drug sensitivity. A total of 138 clinical isolates of fish-pathogenic Edwardsiella tarda, isolated from 1993 to 2003 from different areas of
Korea, were cultured aerobically on tryptose soy broth (TSB) (Difco) supplemented with $1 \%(\mathrm{w} / \mathrm{v}) \mathrm{NaCl}$ at $25^{\circ} \mathrm{C}$ for $18 \mathrm{~h}$. These isolates were diluted in phosphate-buffered saline (PBS) buffer $\left(10^{5}\right.$ colony-forming units per $25 \mu \mathrm{l}$ ) and plated on selective tryptose soy agar (TSA) (Difco) plates containing $60 \mu \mathrm{m} \mathrm{m}^{-1}$ nalidixic acid (NA, Sigma). From the 25 NA-resistant isolates that showed $>20$ colonies on the selective media, 12 isolates were selected to give a wide distribution of years and areas of isolation in this study (see Table 3). These 12 NA-resistant isolates and 1 NA-sensitive isolate, E. tarda GE1 (wild type), were identified by an API 20E kit (BioMerieux) and by conventional laboratory methods, including Gram staining, growth on Salmonella-Shigella agar (SS) (Difco) plates and colony morphology. Minimum inhibitory concentrations (MIC) of quinolones (NA, oxolinic acid, norfloxacin and ciprofloxacin) were determined by the Mueller-Hinton broth (Difco) micro-doubling dilution method (Frech \& Schwarz 2000) on 96-well plates with incubation at $25^{\circ} \mathrm{C}$ for $24 \mathrm{~h}$. Escherichia coli strains and the clinical isolates of $E$. tarda were grown at $37^{\circ} \mathrm{C}$ and $25^{\circ} \mathrm{C}$ in $\mathrm{TSB}$, respectively, and were stored in $20 \%$ glycerol at $-72^{\circ} \mathrm{C}$ until use.

DNA extraction. All of the bacterial species were grown aerobically on TSB supplemented with $1 \%$ $(\mathrm{w} / \mathrm{v}) \mathrm{NaCl}$ at $25^{\circ} \mathrm{C}$ for $18 \mathrm{~h}$. Cultured cells were harvested by centrifugation at $8000 \times g$ for $10 \mathrm{~min}$ and lysed with $5.5 \%$ sodium dodecyl sulfate per $0.125 \mathrm{mg}$ $\mathrm{ml}^{-1}$ proteinase $\mathrm{K}$ (Boehringer Mannheim) solution. Bacterial nucleic acids were extracted by a phenolchloroform-isoamyl alcohol (25:24:1 v/v/v) mixture. The nucleic acids were ethanol precipitated and resuspended in distilled water. The DNA was stored at $-20^{\circ} \mathrm{C}$ until further use.

Primer design and PCR. A degenerate primer set (Table 1) was designed. DGYR-1 (sense primer) and DGYR-4 (anti-sense primer) were derived from the conserved nucleotide sequence of the gyrA genes in 9 bacterial species (Escherichia coli, Aeromonas salmonicida, Pectobacterium carotovorum, Klebsiella pneumoniae, Neisseria gonorrhoeae, Pasteurella multocida, Pseudomonas aeruginosa, Serratia marcescens and Vibrio parahaemolyticus; X57174, L47978, X80798, X16817, U08817, AE006122, L29417, U56906 and AB023569, respectively). These primers were designed with the aid of gene alignment using the MACAW program (Version 2.0.5, National Center for Biotechnology Information, National Institutes of Health, Bethesda, MD, USA). PCR amplification was carried out with a Perkin-Elmer 2400 thermal cycler (PE Applied Biosystems) in a $50 \mu \mathrm{l}$ reaction mixture containing $100 \mathrm{ng}$ of total nucleic acid isolated from 1 or 2 different bacteria, $10 \mathrm{mM}$ Tris- $\mathrm{HCl}_{1} \mathrm{pH} 8.3,50 \mathrm{mM} \mathrm{KCl}, 1.5 \mathrm{mM} \mathrm{MgCl}_{2}$, $0.001 \%$ w/v gelatin, $0.5 \%$ Tween-20, $200 \mu \mathrm{M}$ each 
Table 1. Primers used in this study

\begin{tabular}{|c|c|c|c|c|}
\hline Name & Sequence $\left(5^{\prime} \rightarrow 3^{\prime}\right)$ & Direction & Position & Object \\
\hline DGYR-1 & ATG(C)GGTAATTAC(T)CACCC & Sense & $220-236$ & Screening of gyrA \\
\hline DGYR-4 & $\operatorname{ACCAGA}(T, C) T C A(G) G C A(G) A T C(T) T T C(T) T C$ & Anti-sense & $842-825$ & Screening of gyrA \\
\hline GYRS1 & TGCGCATGGCGAAGATTGCTCATGAG & Sense & $374-399$ & $3^{\prime}$ end walking $\langle 2\rangle^{a}$ \\
\hline GYRS2 & CGGCACTGAACAGATCCCCGACG & Sense & $450-472$ & $3^{\prime}$ end walking $\langle 2\rangle^{a}$ \\
\hline GYRS1R & GCAGGACGTCGGGGATCTGTTCA & Anti-sense & $478-456$ & $5^{\prime}$ end walking $<1>^{a}$ \\
\hline GYRS2R & CTCATGAGCAATCTTCGCCATGCGCA & Anti-sense & $399-374$ & $5^{\prime}$ end walking $<1>^{a}$ \\
\hline GYRS3 & ACATCGATCCGATCATTGAGCTGATC & Sense & 1166-1191 & $3^{\prime}$ end walking $\langle 3\rangle^{a}$ \\
\hline GYRS4 & TCCGGAGTGGCTGGAGCCGACAGTA & Sense & $1299-1322$ & $3^{\prime}$ end walking $\langle 3\rangle^{a}$ \\
\hline SGYR-1 & ATCAACTTGCCGGAGGCCA & Sense & $1813-1831$ & Sequencing \\
\hline SGYR-2 & AGAACGGCTACGGCAAACGC & Sense & $2246-2265$ & Sequencing \\
\hline SGYR-3 & TCGCACCACGCTCAAGGT & Sense & $2860-2877$ & Sequencing \\
\hline SGYR-4 & TGTACATTGCCTCGCCG & Sense & $3468-3484$ & Sequencing \\
\hline SGYR-5 & CTGGCTGTTTGAGCGCA & Sense & $3850-3866$ & Sequencing \\
\hline GYRQ & GATGTTCGGGATGGCCT & Sense & $106-122$ & Detection of gyrA QRDR \\
\hline GYRQR & GCCAACAGCTCATGAGCAAT & Anti-sense & $407-388$ & Detection of gyrA QRDR \\
\hline WGYRS & CGTGAGGCGACGGCTTCAAACTTG & Sense & $(-) 298 \sim(-) 274$ & Cloning of whole gyrA \\
\hline WGYRR & AGACGAAGTATTTCAACGTGGCGC & Anti-sense & $(+) 194 \sim(+) 218$ & Cloning of whole gyrA \\
\hline EWGS & ATCTCTTCGTGGTCTACGTTATG & Sense & $(-) 196 \sim(-) 174$ & Cloning of E. coli gyrA \\
\hline EWGR & ACAAGGAATGTGGCAATGAGTGG & Anti-sense & $(+) 144 \sim(+) 166$ & Cloning of E. coli gyrA \\
\hline
\end{tabular}

dNTP, $1 \mu \mathrm{M}$ each primer and 1.25 U Ampli Taq DNA polymerase (Applied Biosystems). Amplification consisted of 30 cycles at $95^{\circ} \mathrm{C}$ for $30 \mathrm{~s}, 50^{\circ} \mathrm{C}$ for $30 \mathrm{~s}$ and $72^{\circ} \mathrm{C}$ for $1 \mathrm{~min}$ in $0.2 \mathrm{ml}$, thin-walled tubes. The results of amplification were analyzed by $1.5 \%$ agarose gel electrophoresis. The $623 \mathrm{bp}$ PCR product was purified by agarose gel electrophoresis using the Prep-A-Gene DNA Purification system (Bio-Rad Laboratories) and cloned into the TOPO-TA vector (Invitrogen) following the instructions of the manufacturer. The cloned fragment was sequenced using the Big Dye Terminator Cycle DNA Sequencing Kit (ABI PRISM, PE Applied Biosystems) and an automatic sequencer (Applied Biosystems). Nucleotide sequences were compared based upon gene alignment using the MACAW program for gyrA gene sequences of different bacterial species.

Cloning of the Edwardsiella tarda gyrA gene. A commercially available, in vitro cloning system (Takara Shuzo, Shiga, Japan) was used to amplify the previously unknown region of genomic DNA flanking the gyrA gene, based on PCR using a cassette (a double-stranded synthetic oligonucleotide with a $5^{\prime}$-end dephosphorylated restriction site) and cassette primers after a slight modification of the method in the manufacturer's instructions.

Preparation of the cassette-ligated bacterial DNA mixture: Edwardsiella tarda DNA (2.5 $\mu \mathrm{g})$ was isolated and was completely digested by $30 \mathrm{U}$ of the appropriate restriction enzymes. The digested bacterial nucleic acids were precipitated with cold ethanol and resuspended in $5 \mu$ l of sterile, distilled water. The nucleic acids were mixed with the ligation components
(Takara Shuzo); $15 \mu \mathrm{l}$ of Ligation Solution I, $7.5 \mu \mathrm{l}$ of Ligation Solution II and a cassette corresponding to the restriction enzyme were used to digest the bacterial DNA. After incubation at $16^{\circ} \mathrm{C}$ for $30 \mathrm{~min}$, the ligated nucleic acids were precipitated with cold ethanol and resuspended in $200 \mu \mathrm{l}$ of sterile, distilled water. After heating at $94^{\circ} \mathrm{C}$ for $10 \mathrm{~min}$, the nucleic acids were use as a template for first PCR in cassette ligationmediated PCR described below. We used ECORI for the 5' gene extension, and then PstI and SalI sequentially for the 3' extension.

Cassette ligation-mediated PCR: Primers GYRS1R and GYRS2R for 5' end walking were derived from the sequence of $623 \mathrm{bp}$ PCR products sequenced in the above experiment and corresponded to Bases 478 to 456 and Bases 399 to 374 from the $5^{\prime}$-end of the amplified gyrA region. Cassette Primers C1 (5'-GTACATATTGTCGTTAGAACGCGTAATACGACTCA-3') and C2 (5'-CGTTAGAACGCGTAAT-ACGACTCACTATAGGGAGA-3') (Takara Shuzo) were derived from the common nucleotide sequence of the cassettes designed for various restriction enzymes. The first PCR amplification was carried out with a Perkin-Elmer 2400 thermal cycler in a $50 \mu \mathrm{l}$ reaction containing $34.5 \mu \mathrm{l}$ of Edwardsiella tarda nucleic acids (ECoRI cassetteligated E. tarda DNA mixture), 1× Takara LA buffer, 2.5 U Takara LA Taq polymerase, $400 \mu \mathrm{M}$ of each dNTP mixture, 10 pmol C1 primer and GYRS1R primer. After $10 \mathrm{~min}$ of heating at $94^{\circ} \mathrm{C}$, amplification consisted of 30 cycles at $94^{\circ} \mathrm{C}$ for $30 \mathrm{~s}, 55^{\circ} \mathrm{C}$ for $30 \mathrm{~s}$ and $72^{\circ} \mathrm{C}$ for $4 \mathrm{~min}$ in $0.2 \mathrm{ml}$, thin-walled tubes. Using the same conditions, a second PCR was performed using the Primers $\mathrm{C} 2$ and GYRS2R and $1 \mu \mathrm{l}$ of the product of the first PCR 
amplification as a template. The PCR products were cloned and sequenced as described above. The 3 '-end gene extensions obtained from other cassette-ligated $E$. tarda DNA mixtures (prepared sequentially with PstI, SalI treatments and their corresponding cassettes), and newly designed primers (GYRS1 and GYRS2, GYRS3 and GYRS4 for 3'-end walking) derived from the sequence of cloned fragments. With this method, 3 sequential cloning steps by cassette ligation-mediated PCR with ECoRI, PstI and SalI cassette-ligated bacterial DNA were performed to obtain the complete E. tarda gyrA gene and flanking regions (Fig. 1).

Cloning of the full-length Edwardsiella tarda gyrA gene. The full-length gyrA gene and the contiguously extended regions (3153 bp) were amplified from the chromosomal DNA of E. tarda GE1 (wild type) and RED7 (mutant type) by PCR with the primer set WGYRS/WGYRR (Table 1). Chromosomal DNA of Escherichia coli K-12 HB101 was also used to amplify the full-length E. coli gyrA gene (2980 bp) (Swanberg \& Wang 1987) in PCR with the primer set EWGS/EWGR (Table 1). PCR amplification was carried out as described above. The resulting amplicons were cloned into the TOPO-TA vector following the instructions of the manufacturer and were introduced into E. coli TOPO by transformation. Three different plasmids, pGE1, pRED7 and pHB101 extracted from E. coli TOPO transformants by the method of Kado \& Liu (1981), were used to transform a temperature-sensitive gyrA mutant, E. coli KNK453 (Kreuzer \& Cozzarelli 1979) and designated E. coli KNK453 (pGE1), E. coli KNK453 (pRED7) and E. coli KNK453 (pHB101), respectively (see Table 4).

\section{RESULTS}

\section{Cloning of the Edwardsiella tarda gyrA gene}

The 4505-bp nucleotide sequence of the Edwardsiella tarda gyrA gene and flanking regions has been deposited in GenBank under Accession Number DQ019315. The organization of the E. tarda gyrA gene locus is shown in Fig. 1, with the restriction enzyme recognition sites and positions of primers used for each extension in the cassette ligation-mediated PCR shown. Sequence positions are given as negative numbers, indicating the distance upstream from the gyrA gene translation start codon, and as positive numbers, indicating the distance downstream from the gyrA gene translation termination codon.

To confirm that this ORF is the gyrA gene of Edwardsiella tarda, the nucleotide and deduced amino acid sequences were compared with those of other bacterial species and very high identities, especially to those of Gram-negative bacteria, using the BioEdit program (Version 5.0.9, Dept of Microbiology, North Carolina State University, Raleigh, NC, USA) (Table 2). The higher nucleotide sequence (deduced amino acid sequence) identities between the region suspected as a QRDR in this ORF, from 199 to 318 (67 to 106), agreed with the characteristics of QRDR known to be a conserved region in gyrA of other bacteria. Additionally, this ORF exhibited relatively high identity with parC sequences of other bacteria, but less than those found in the comparison with gyrA genes (Table 2). All of these results indicate that the ORF that contained the amplicon of $623 \mathrm{bp}$ was the E. tarda gyrA gene.

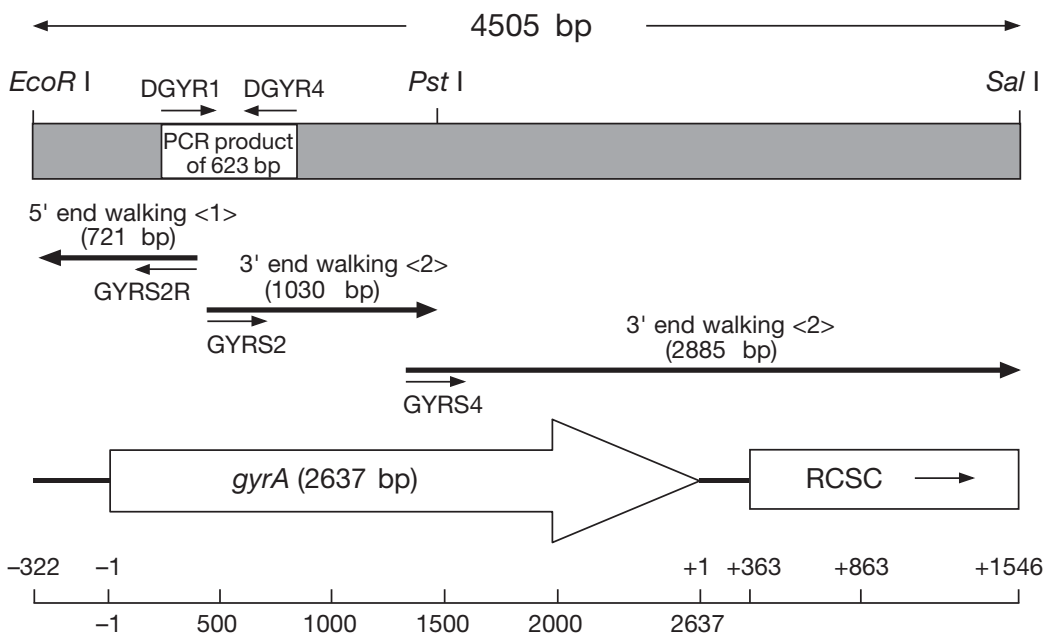

Fig. 1. Edwardsiella tarda. Restriction map and organization of the gyrA locus. Thin arrows indicate positions of the primers used for cloning of the gyrA gene. Thick arrows indicate the DNA fragments produced in cassette ligation-mediated PCR by the indicated restriction enzymes and walking directions. Complete nucleotide sequences are given in GenBank (Accession Number: DQ019315) (RCSC, capsular synthesis regulator component)

\section{Sequence analysis of the Edwardsiella tarda gyrA gene}

The gyrA gene of Edwardsiellla tarda was larger than that of Escherichia coli, containing 3 more amino acids. In the analysis of the nucleotide sequence, we found the presence of a ribosome binding site $(-16$ from the ATG codon), a putative promoter region $(-25$ from the ATG codon) and 3 pairs of inverted repeat sequences involved in the regulation of transcription (-203/-86 and $-199 /-44$ from the ATG codon and $+20 /+37$ from the termination codon). In addition, residues, the substitution of which confers quinolone resistance in $E$. coli, notably, Tyr ${ }^{122}, \mathrm{Ala}^{67}, \mathrm{Gly}^{81}, \mathrm{Ser}^{83}$, $\mathrm{Asp}^{87}$ and $\mathrm{Gln}^{106}$, were conserved in $E$. tarda gyrA at identical coordinates 
Table 2. Identity of the nucleotide and deduced amino acid sequences of gyrA gene in Edwardsiella tarda compared with those of other bacterial strains. QRDR: quinolone-resistance-determining region

\begin{tabular}{|c|c|c|c|c|c|c|}
\hline & \multirow[t]{2}{*}{ Organism } & \multirow[t]{2}{*}{ Accession $n^{a}$} & \multicolumn{2}{|c|}{ Nucleotide sequence (\%) } & \multicolumn{2}{|c|}{ Deduced amino acid sequence (\%) } \\
\hline & & & Whole GyrA & QRDR & Whole GyrA & QRDR \\
\hline \multirow[t]{9}{*}{$\operatorname{Gram}(-)$} & Escherichia coli & X57174 & $78(49)^{\mathrm{b}}$ & 84 & $85(30)$ & 100 \\
\hline & Aeromonas salmonicida & L47978 & 71 & 83 & 71 & 93 \\
\hline & Pectobacterium carotovorum & X80798 & 78 & 83 & 85 & 97 \\
\hline & Klebsiella pneumoniae & X16817 & 80 & 84 & 86 & 97 \\
\hline & Neisseria gonorrhoeae & U08817 & $59(49)$ & 77 & $51(29)$ & 85 \\
\hline & Pasteurella multocida & AE006122 & 64 & 88 & 72 & 95 \\
\hline & Pseudomonas aeruginosa & L29417 & $68(52)$ & 78 & $63(32)$ & 97 \\
\hline & Serratia marcescens & U56906 & $83(53)$ & 91 & $86(31)$ & 100 \\
\hline & Vibrio parahaemolyticus & AB023569 & $70(50)$ & 85 & $77(31)$ & 100 \\
\hline \multirow[t]{3}{*}{$\operatorname{Gram}(+)$} & Streptococcus pneumoniae & AY157689 & $52(49)$ & 65 & $46(34)$ & 68 \\
\hline & Campylobacter jejuni & LO4566 & 48 & 63 & 45 & 70 \\
\hline & Mycoplasma hominis & U59880 & 45 & 65 & 39 & 75 \\
\hline
\end{tabular}

(Horowitz \& Wang 1987, Swanberg \& Wang 1987, Oppegard \& Sorum 1996). However, the nucleotide sequences of the 5' and 3' end flanking regions of the E. tarda gyrA gene did not show any homologies to those of other bacterial $g y r B$ genes and this suggests that the gyrase genes $g y r B / g y r A$ are non-contiguous in the genome of E. tarda. We also determined the partial nucleotide sequences of another putative ORF cloned with the gyrA gene by 3 ' end DNA walking and found it to show $49 \%$ nucleotide sequence identity with that of the RCSC in E. Coli (Fig. 1).

\section{Characterization of gyrA mutations in quinolone- resistant clinical isolates of Edwardsiella tarda}

In order to examine the role of gyrA in quinoloneresistant Edwardsiella tarda, 12 strains were selected from 25 clinical isolates showing a MIC of $>60 \mu \mathrm{g} \mathrm{ml}^{-1}$ of NA. These quinolone-resistant E. tarda strains were also resistant to various quinolone antibiotics (Table 3).

A 302-bp gyrA region spanning Nucleotides 106 to 407 was amplified by single-step PCR with specific primers, GYRQ/GYRQR, from quinolone-resistant Edwardsiella tarda isolates. This region encompasses the sequence equivalent to the QRDR of Escherichia coli gyrA (Residues 201 to 318) and flanking regions. The amplified sequences were ligated into the TOPOTA vector, and the inserts were sequenced and compared. Table 3 presents the nucleotide and amino acid changes in the QRDR of the gyrA genes from clinical isolates. All 12 clinical isolates resistant to quinolone carried a single nucleotide change compared to the quinolone-susceptible E. tarda GE1. One AGC to CGC and 11 AGC to AGA alterations were found at Codon 83 in 12 quinolone-resistance E. tarda isolates, all of which would result in a Ser to Arg substitution in gyrA. Apart from this substitution, the nucleotide sequence of the QRDR in all quinolone-resistant isolates was identical to that of the susceptible strain. However, for each of the quinolone-resistant isolates, there were significant variations in the MICs of OA, NOR and CIP (Table 3). It cannot be excluded that other mechanisms may also contribute to change the ultimate MICs of quinolone antibacterial agents in quinolone-resistant E. tarda.

\section{Expression of Edwardsiella tarda gyrA in Escherichia coli gyrA mutants}

The PCR products which were amplified using DNA extracted from Edwardsiella tarda GE1 and RED7 isolates as templates with WGYRS/WGYRR as primers (Table 1) were cloned into the TOPO-TA vector. These plasmids contained the full-length E. tarda gyrA gene and the contiguously extended regions that have the potential to regulate the expression of the structural gyrA gene. E. coli KNK453 transformed with pGE1 (bearing the wild-type gyrA) exhibited growth on TSA plates at both the permissive temperature of $30^{\circ} \mathrm{C}$ and the non-permissive temperature of $42^{\circ} \mathrm{C}$ (Table 4). Transformation with pRED7 (bearing a gyrA gene with $\mathrm{Arg}^{83}$ ) increased the resistance of E. coli KNK453 to NA and $\mathrm{OA}$ at $42^{\circ} \mathrm{C}$. The level of resistance was much lower than that of the E. tarda RED7 isolate, but significantly higher than that of E. coli KNK453 transformed with pGE1 at $42^{\circ} \mathrm{C}$. 
Table 3. Susceptibility to quinolones and mutations in the QRDR of gyrA genes of Edwardsiella tarda isolates (MIC, minimum inhibitory concentrations; NA, nalidixic acid; OA, oxolinic acid; NOR, norfloxacin; CIP, ciprofloxacin)

\begin{tabular}{|c|c|c|c|c|c|c|c|}
\hline \multirow[t]{2}{*}{ Strain } & \multirow[t]{2}{*}{ Isolation } & \multirow{2}{*}{$\overline{\mathrm{NA}}$} & \multicolumn{3}{|c|}{$\operatorname{MIC}\left(\mu \mathrm{g} \mathrm{ml}^{-1}\right)$} & \multicolumn{2}{|c|}{ Mutation in $g y r A$} \\
\hline & & & $\mathrm{OA}$ & NOR & CIP & $\begin{array}{l}\text { Amino } \\
\text { acid }\end{array}$ & $\begin{array}{c}\text { Base } \\
\text { change }\end{array}$ \\
\hline GE1 & 1994, Kujedo & 2 & 0.13 & 0.03 & 0.008 & 83(Ser) & AGC \\
\hline RED7 & 1994, Yosu & $\geq 512$ & 2 & 0.31 & 0.06 & 83(SER $\rightarrow$ Arg) & AGA \\
\hline RE1 & 1995, Kwangju & 64 & 0.5 & 0.08 & 0.03 & 83(SER $\rightarrow$ Arg) & CGC \\
\hline RE8 & 1995, Pohang & $\geq 512$ & 4 & 0.31 & 0.06 & 83(SER $\rightarrow$ Arg) & AGA \\
\hline LE2 & 1995, Namhae & $\geq 512$ & 2 & 0.31 & 0.13 & 83(SER $\rightarrow$ Arg) & AGA \\
\hline JH4 & 1996, Tongyoung & $\geq 512$ & 1 & 0.16 & 0.06 & 83(SER $\rightarrow$ Arg) & AGA \\
\hline KFE & 1997, Gampo & 64 & 2 & 0.13 & 0.06 & 83(SER $\rightarrow$ Arg) & AGA \\
\hline JH9 & 1999, Tongyoung & $\geq 512$ & 2 & 0.16 & 0.06 & 83(SER $\rightarrow$ Arg) & AGA \\
\hline JDE2 & 2000, Yosu & 256 & 1 & 0.63 & 0.06 & 83 (SER $\rightarrow$ Arg) & AGA \\
\hline JDE30 & 2001, Namhae & 256 & 1 & 1.25 & 0.06 & 83(SER $\rightarrow$ Arg) & AGA \\
\hline JDE37 & 2002, Kuryongpo & $\geq 512$ & 4 & 1.25 & 1.25 & 83(SER $\rightarrow$ Arg) & AGA \\
\hline CJE13 & 2003, Jejudo & $\geq 512$ & 2 & 0.5 & 0.25 & 83(SER $\rightarrow$ Arg) & AGA \\
\hline JDE45 & 2003, Kujedo & $\geq 512$ & 4 & 0.5 & 0.13 & 83(SER $\rightarrow$ Arg) & AGA \\
\hline
\end{tabular}

Table 4. MICs of quinolones for Escherichia coli strains K-12 HB101, KNK453, and KNK453 with different transforming plasmids. MICs were determined at $42^{\circ} \mathrm{C}$, except for KNK453 without plasmid $\left(30^{\circ} \mathrm{C}\right)$ (NA, nalidixic acid; OA, oxolinic acid; NOR, norfloxacin; CIP, ciprofloxacin)

\begin{tabular}{|c|c|c|c|c|c|c|c|c|}
\hline \multirow{2}{*}{ Strain } & \multicolumn{4}{|c|}{$\mathrm{MIC}\left(\mu \mathrm{g} \mathrm{ml}^{-1}\right)$ at $30^{\circ} \mathrm{C}$} & \multicolumn{4}{|c|}{$\mathrm{MIC}\left(\mu \mathrm{g} \mathrm{ml}^{-1}\right)$ at $42^{\circ} \mathrm{C}$} \\
\hline & NA & $\mathrm{OA}$ & NOR & CIP & NA & $\mathrm{OA}$ & NOR & CIP \\
\hline K-12 HB101 & 4 & 0.13 & 0.03 & 0.008 & 4 & 0.13 & 0.03 & 0.008 \\
\hline KNK453 & 2 & 0.06 & 0.015 & 0.015 & & & & \\
\hline KNK (pHB101) & 4 & 0.13 & 0.03 & 0.008 & 2 & 0.06 & 0.015 & 0.015 \\
\hline KNK (pGE1) & 4 & 0.06 & 0.03 & 0.015 & 2 & 0.06 & 0.015 & 0.008 \\
\hline KNK (pRED7) & 1 & 0.06 & 0.015 & 0.008 & 32 & 0.5 & 0.15 & 0.015 \\
\hline
\end{tabular}

\section{DISCUSSION}

The approach used to determine the nucleotide sequence of the Edwardsiella tarda gyrA gene is based on conservation of the QRDR and its flanking regions and thus would be applicable to sequence determination of the gyrA or parC homologues in many bacterial species (Peng \& Marians 1993).

Sequence analysis of the Edwardsiella tarda gyrA gene revealed a ribosome-binding site with homology to the Escherichia coli Shine-Dalgarno consensus sequence (GAGGG) located $16 \mathrm{bp}$ upstream from the ATG translation initiation codon. At 9 bp upstream of the Shine-Dalgarno sequence, there was a region (TAATTA) that is the same as the -10 Aeromonas salmonicida promoter and similar to the -10 E. coli promoter consensus sequences (TATAAT). Further upstream, although it was not apparent, a putative -35 region (TGTATT) similar to that of Helicobacter pylori (TTGATT) (Moore et al. 1995) was observed. However, the sequences found in the -35 gyrA promoter regions in other bacteria, such as the conserved form (GTT-
TACC) in E. coli (Swanberg \& Wang 1987), Klebsiella pneumoniae (Dimri \& Das 1990) and Bacillus subtilis (Moriya et al. 1985), or as other forms ATTTTCC, GTTTGCC, GTTTCCC and GTTTAAG in Serratia marcescens (Kim et al. 1998), Pseudomonas aeruginosa (Kureishi et al. 1994), Erwinia carotovora (Rosanas et al. 1995) and A. salmonicida (Oppegard \& Sorum 1996), respectively, were not found.

Two pairs of inverted repeat sequences that may form cruciform structures involved in the regulation of transcription were identified in the upstream region of the Edwardsiella tarda gyrA gene. These are the AAAGAC/GTCTTT pair, located at -203/ -86 and the ACCCTC/GAGGGT pair, located at -199/-44 from the start codon, and could form a cruciform structures with unpaired loops of 111 and 149 nucleotides, respectively. The presence of these inverted repeat sequences indicated that supercoilingdependent regulation of gyrA transcription may work in E. tarda, as suggested for Escherichia coli (Horowitz \& Loeb 1988). Inverted repeat sequences have also been identified in gyrA promoters, in Aeromonas salmonicida (Oppegard \& Sorum 1996), Pseudomonas aeruginosa (Kureishi et al. 1994) and Klebsiella pneumoniae (Dimri \& Das 1990). Another inverted repeat sequence, AAGGGC/ GCCCTT, located $+20 /+37$ from the translational stop codon TAA, may act as a transcriptional termination signal by the formation of a loop structure with 11 unpaired nucleotides (Oppegard \& Sorum 1996).

In the alignment of the deduced amino acid sequence, we could not find the intragenic stretches present in the 3'-end of gyrA genes from Campylobacter jejuni, Pseudomonas aeruginosa and Helicobacter pylori (Wang et al. 1993, Kureishi et al. 1994, Moore et al. 1995). The catalytic Tyr ${ }^{122}$ involved in DNA breakage and reunion was also present, as in Escherichia coli and other bacteria (Horowitz \& Wang 1987). Additional residues, the substitution of which confers quinolone resistance in E. coli, notably, Ala ${ }^{67}, \mathrm{Gly}^{81}, \mathrm{Ser}^{83}, \mathrm{Asp}^{87}$ and $\mathrm{Gln}^{106}$, were also conserved in Edwardsiella tarda gyrA.

However, upstream and downstream regions of the Edwardsiella tarda gyrA gene did not show any homologies to the $g y r B$ gene of other bacterial species and failed to reveal if the gyrA and gyrB genes are contiguous. Non-contiguous gyrase genes have been 
found to be common in many Gram-negative bacteria (Dimri \& Das 1990, Kureishi et al. 1994, Wang et al. 1993). On the other hand, contiguous gyrB/gyrA gyrase genes have been identified in Mycoplasma pneumoniae and other Gram-positive bacteria (Colman et al. 1990, Moriya et al. 1985).

Amino acid residues, $\operatorname{Ser}^{83}$ and $\mathrm{Glu}^{87}$, of Escherichia coli gyrA have been shown to be hot spots for quinolone resistance (Vila et al. 1994, Yolanda et al. 2003). We examined the similarities among gyrA genes from Edwardsiella tarda isolates for quinolone resistance and found only a single substitution in all quinolone-resistant E. tarda isolates of this study: $\mathrm{Ser}^{83} \rightarrow$ Arg. The $\mathrm{Ser}^{83} \rightarrow$ Arg substitution has also been observed at a high frequency in quinolone-resistant clinical isolates of Yersinia ruckeri (Gibello et al. 2004) and as one of the mutations in quinolone-resistant clinical isolates of Enterococcus faecalis and Aeromonas salmonicida. (Korten et al. 1994, Tankovic et al. 1996). Additional studies of the alteration of gyrA using E. tarda mutants obtained in in vitro conditions are ongoing in our laboratory.

To examine the complementation of the Escherichia coli gyrA mutant, the full length the gyrA gene of Edwardsiella tarda was cloned and used to transform E. coli KNK453, a temperature-sensitive gyrA mutant. Transformation with the plasmid pRED7 (mutant type) was able to restore growth and induce resistance to NA and OA in E. coli KNK453 at $42^{\circ} \mathrm{C}$. The level of resistance was significantly higher than that of $E$. coli KNK453 transformed with pGE1 (wild type) at $42^{\circ} \mathrm{C}$, but did not reach the levels of the E. tarda RED7 isolate. These results indicated that: (1) the complete gyrA gene was successfully cloned, (2) the promoter region of the E. tarda gyrA gene was active in the E. Coli system, (3) an E. tarda gyrA-E. coli gyrB holoenzyme complex is functionally active and (4) the variable MICs of quinolones for the quinolone-resistant E. tarda isolates might be explained by additional mechanisms, including mutations in other DNA gyrase (or TOPO IV) genes, gyrB, parC, parE, or those that can cause decreased drug permeability or increased drug efflux (Nakamura 1997). Further study is required to determine between these possibilities. However, all quinolone-resistant isolates had a mutation within the QRDR, suggesting that the primary target for resistance is an alteration in the gyrA gene rather than in other potential genes.

Additional characterization of the Edwardsiella tarda gyrA gene reported here should facilitate further understanding of this important fish pathogenic bacteria and its quinolone resistance. However, the use of quinolones in Asian aquaculture should be avoided as much as possible, to prevent the emergence and spread of quinolone-resistant strains of E. tarda in the aquatic environment.
Acknowledgements. This work was supported by a grant from the Ministry of Maritime Affairs and Fisheries of Korea (KSGP of 2003).

\section{LITERATURE CITED}

Adams DE, Shekhtman EM, Zechiedrich EL, Schmid NB, Cozzarelli NR (1992) The role of topoisomerase IV in partitioning bacterial replicons and the structure of catenated intermediates in DNA replication. Cell 71:277-288

Aoki T (1988) Drug-resistant plasmids from fish pathogens. Microbiol Sci Rev 5:219-223

Baxa DV, Kawai K, Ando H, Kusuda R (1985) Edwardsiella tarda and Staphylococcus aureus isolated from cultured red sea bream. Rep Biol Inst 7:1-8

Bébéar CM, Grau O, Charron A, Renaudin H, Gruson D, Bébéar C (2000) Cloning and nucleotide sequence of the DNA gyrase (gyrA) gene from Mycoplasma hominis and characterization of quinolone-resistant mutants selected in vitro with trovafloxacin. Antimicrob Agents Chemother 44:2719-2727

Capilla S, Ruiz J, Goni P, Castillo J, Rubio MC, Jimenez de Anta MT, Gomez-Lus R, Vila J (2004) Characterization of the molecular mechanisms of quinolone resistance in Yersinia enterocolitica O:3 clinical isolates. J Antimicrob Chemother 53:1068-1071

Chen JD, Huang SL (1996) Hemoysin from Edwardsilla tarda strain ET-16 isolated from eel Anguilla japonica identified as a hole-forming toxin. Fish Sci (Tokyo) 62:538-542

Colman SD, Hu PC, Bott KF (1990) Mycoplasma pneumoniae DNA gyrase genes. Mol Microbiol 4:1129-1134

Dimri GP, Das HK (1990) Cloning and sequence analysis of gyrA gene of Klebsiella pneumoniae. Nucleic Acids Res 18:151-156

Drlica K, Zhao XL (1997) DNA gyrase, topoisomerase IV, and the 4-quinolones. Microbiol Mol Biol Rev 61:377-392

Frech G, Schwarz S (2000) Molecular analysis of tetracycline resistance in Salmonella enterica subsp. enterica serovars Typhimurium, Enteritidis, Dublin, Choleraesuis, Hadar and Saintpaul: construction and application of specific gene probes. J Appl Microbiol 89:633-641

Gibello A, Porrero MC, Blanco MM, Vela AI, Liébana P, Moreno MA, Fernández-Garayzábal JF, Domínguez L (2004) Analysis of the gyrA gene of clinical Yersinia ruckeri isolates with reduced susceptibility to quinolones. Appl Environ Microbiol 70:599-602

Goni-Urriza M, Arpin C, Capdepuy M, Dubois V, Caumette P, Quentin C (2002) Type II topoisomerase quinolone resistance-determining regions of Aeromonas caviae, A. hydrophila, and A. sobria complexes and mutations associated with quinolone resistance. Antimicrob Agents Chemother 46:350-359

Herman RL, Bullock GL (1986) Pathology caused by the bacterium Edwardsilla tarda in striped bass. Trans Am Fish Soc 115:232-235

Hooper DC (1998) Bacterial topoisomerases, anti-topoisomerases, and anti-topoisomerase resistance. Clin Infect Dis 27: S54-S63

Horii T, Suzuki Y, Monji A, Morita M and 6 others (2003) Detection of mutations in quinolone resistance-determining regions in levofloxacin and methicillin-resistant Staphylococcus aureus: effects of the mutations on fluoroquinolone MICs. Diagn Microbiol Infect Dis 46:139-145

Horowitz MS, Loeb LA (1988) An E. coli promoter that regulates transcription by DNA superhelix-induced cruciform extrusion. Science 241:703-705 
Horowitz DS, Wang JC (1987) Mapping the active site tyrosine of Escherichia coli DNA gyrase. J Biol Chem 262: 5339-5344

Janda JM, Abott SL (1993) Expression of an iron-regulated hemolysin in Edwardsilla tarda. FEMS Microbiol Lett 111: $275-280$

Kado CI, Liu ST (1981) Rapid procedure for detection and isolation of large and small plasmids. J Bacteriol 145: 1365-1373

Kim JH, Cho EH, Kim KS, Kim HY, Kim YM (1998) Cloning and nucleotide sequence of the DNA gyrase gyrA gene from Serratia marcescens and characterization of mutations in gyrA of quinolone-resistant clinical isolates. Antimicrob Agents Chemother 42:190-193

Korten V, Huang WM, Murray BE (1994) Analysis by PCR and direct DNA sequencing of gyrA mutations associated with fluoroquinolone resistance in Enterococcus faecalis. Antimicrob Agents Chemother 38:2091-2094

Kreuzer KN, Cozzarelli NR (1979) Escherichia coli mutants thermosensitive for deoxyribonucleic acid gyrase subunit A: effects on deoxyribonucleic acid replication, transcription, and bacteriophage growth. J Bacteriol 140:424-435

Kubota SS, Kaige N, Miyazaki T, Miyashita T (1981) Histopathological studies on edwardsiellosis of tilapia. Bull Fac Fish Mie Univ 9:155-165

Kureishi A, Diver JM, Beckthold B, Schollaardt T, Bryan LE (1994) Cloning and nucleotide sequence of Pseudomonas aeruginosa DNA gyrase gyrA gene from strain PAO1 and quinolone-resistant clinical isolates. Antimicrob Agents Chemother 38:1944-1952

Moore RA, Beckthold B, Wkureishiong SA, Bryan LE (1995) Nucleotide sequence of the gyrA gene and characterization of ciprofloxacin-resistant mutants of Helicobacter pylori. Antimicrob Agents Chemother 39:107-111

Moriya S, Ogasawara N, Yoshikawa H (1985) Structure and function of the region of the replication origin of the Bacillus subtilis chromosome. III. Nucleotide sequence of some $10 \# 000$ base pairs in the origin region. Nucleic Acids Res 13:2251-2265

Nakamura S (1997) Mechanisms of quinolone resistance. J Infect Chemother 3:128-138

Editorial responsibility: Carey Cunningham, Aberdeen, UK
Nakatsugawa T (1983) Edwardsilla tarda isolated from cultured young flounder. Fish Pathol 18:99-101

Oppegard H, Sorum H (1996) Cloning and nucleotide sequence of the DNA gyrase gyrA gene from the fish pathogen Aeromonas salmonicida. Antimicrob Agents Chemother 40:1126-1133

Peng H, Marians KV (1993) Escherichia coli topoisomerase IV. Purification, characterization, subunit structure, and subunit interactions. J Biol Chem 268:24481-24490

Reinhardt JF, Fowlston S, Jones J, George WL (1985) Comparative in vitro activities of selected antimicrobial agents against Edwardsiella tarda. Antimicrob Agents Chemother 27:966-967

Rosanas A, Barbe J, Gibert I (1995) Cloning and sequencing of the gyrA gene from the plant pathogen Erwinia carotovora. Gene 161:11-14

Stock I, Wiedemann B (2001) Natural antibiotic susceptibilities of Edwardsiella tarda, E. ictaluri, and E. hoshinae. Antimicrob Agents Chemother 45:2245-2255

Swanberg SL, Wang JC (1987) Cloning and sequencing of the Escherichia coli gyrA gene coding for the A subunit of DNA gyrase. J Mol Biol 197:729-736

Tankovic J, Mahjoubi F, Courvalin P, Duval J, Leclerco R (1996) Development of fluoroquinolone resistance in Enterococcus faecalis and role of mutations in the DNA gyrase gyrA gene. Antimicrob Agents Chemother 40: $2558-2561$

Vila J, Ruiz J, Marco F, Barcelo A, Goni P, Giralt E, Jimenez de Anta T (1994) Association between double mutation in gyrA gene of ciprofloxacin-resistant clinical isolates of Escherichia coli and MICs. Antimicrob Agents Chemother 38:2477-2479

Wang Y, Huang WM, Taylor DE (1993) Cloning and nucleotide sequence of the Campylobacter jejuni gyrA gene and characterization of quinolone resistance mutations. Antimicrob Agents Chemother 37:457-463

Yolanda S, Myriam Z, Laura B, Fernanda RL, Carmen T (2003) Mutations in gyrA and parC genes in nalidixic acidresistant Escherichia coli strains from food products, humans and animals. J Antimicrob Chemother 51: 1001-1010

Submitted: January 20, 2005; Accepted: June 21, 2005

Proofs received from author(s): November 2, 2005 